\title{
Sugar Uptake during Germination of Streptomyces antibioticus Spores
}

\author{
By JOSÉ ANTONIO SALAS AND CARLOS HARDISSON* \\ Departamento de Microbiologia, Universidad de Oviedo, Oviedo, Spain
}

(Received 7 October 1980; revised 24 November 1980)

\begin{abstract}
Glucose, galactose and fructose uptake was studied during the germination of Streptomyces antibioticus spores. Dormant spores had only the glucose uptake system, whatever the carbon source of the sporulation medium. Even when sporulation took place in the presence of galactose or fructose as the sole carbon and energy source neither galactose nor fructose uptake was detected. During germination the uptake systems for these two sugars were inducible by the appropriate sugar; the induction time was less when the germination process was more advanced. Synthesis of all uptake systems was immediately blocked by the addition of inhibitors of protein or RNA synthesis. Vegetative mycelium in the exponential phase of growth showed a similar pattern of sugar uptake. Glucose caused repression of the galactose and fructose uptake systems. The three sugar uptake systems were strongly inhibited by potassium cyanide, 2,4-dinitrophenol and $p$-chloromercuribenzoate, and showed optimum temperatures for uptake at $40^{\circ} \mathrm{C}$ (glucose) and $45^{\circ} \mathrm{C}$ (galactose and fructose).
\end{abstract}

\section{INTRODUCTION}

Germination of Streptomyces antibioticus spores can be divided into three different morphological and biochemical stages (Hardisson et al., 1978). The first stage, phase darkening, is triggered by addition of divalent cations and is an energy-requiring process. The second stage, swelling, is dependent upon an exogenous carbon source and is marked by an increased metabolic and biosynthetic activity. Germ tube emergence is the last event and this requires the presence of both a carbon and nitrogen source (Hardisson et al., 1978). Several different aspects of the germination of Streptomyces spores have been studied (Attwell \& Cross, 1973; Kalakoutskii \& Pouzharitskaja, 1973; Hirsch \& Ensign, 1975, 1976a, $b$; Hardisson et al., 1978, 1980), but one important aspect, sugar uptake during germination, has received little attention.

Amino acid transport in Streptomyces has been investigated in great detail using mycelium of S. hydrogenans (Gross \& Burkhardt, 1973; Ring et al., 1976, 1977). However, only two reports have been published on sugar transport, by mycelium of $S$. violaceoruber (Sabater \& Asensio, 1973) and of $S$. venezuelae (Tang, 1977).

The aim of this work was to study the uptake of glucose, galactose and fructose by dormant spores of $S$. antibioticus, and the development of the sugar uptake systems during germination of the spores.

\section{METHODS}

Micro-organism and culture conditions. The micro-organism used was Streptomyces antibioticus ATCC 11891. Conditions for sporulation, preparation of spore suspensions and germination were as previously described (Hardisson et al., 1978). In many experiments, a minimal synthetic medium (MSM) was used instead of the complex medium GAE (glucose/asparagine/yeast extract/salts). The composition of MSM medium was $\left(\mathrm{g}^{-1}\right)$ : $\mathrm{K}_{2} \mathrm{HPO}_{4}, 0.5 ; \mathrm{MgSO}_{4} .7 \mathrm{H}_{2} \mathrm{O}, 0.5 ; \mathrm{FeSO}_{4} .7 \mathrm{H}_{2} \mathrm{O}, 0.01$; carbon source, $10.0 ;\left(\mathrm{NH}_{4}\right)_{2} \mathrm{SO}_{4}$ (for germination) or $\mathrm{NaNO}_{3}$ (for sporulation), 2.0; agar (for sporulation), 20.0. 
Sugar uptake measurements. At different times during germination, samples were withdrawn and centrifuged at

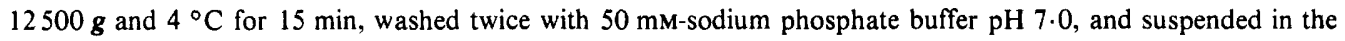
same buffer at a concentration of $2.0 \times 10^{8}$ spores $\mathrm{ml}^{-1}$.

Uptake of ${ }^{3} \mathrm{H}$-labelled substrates (D-[1- $\left.{ }^{3} \mathrm{H}\right]$ glucose, $8.3 \mathrm{Ci} \mathrm{mmol}^{-1}, 307 \mathrm{GBq} \mathrm{mmol}{ }^{-1}$; D-[1- $\left.{ }^{3} \mathrm{H}\right]$ galactose, $12.4 \mathrm{Ci} \mathrm{mmol}{ }^{-1}, 459 \mathrm{GBq} \mathrm{mmol}^{-1}$; D-[6(n)- $\left.{ }^{3} \mathrm{H}\right]$ fructose, $1.6 \mathrm{Ci} \mathrm{mmol}^{-1}, 59 \mathrm{GBq} \mathrm{mmol}^{-1} ; 2-$ deoxy-D-[1- $\left.{ }^{3} \mathrm{H}\right]-$ glucose, $20.2 \mathrm{Ci} \mathrm{mmol}^{-1}, 747 \mathrm{GBq} \mathrm{mmol}^{-1}$; all from The Radiochemical Centre, Amersham) by whole cells was determined by measuring the radioactivity retained on Whatman GF/A glass-fibre filters. All uptake studies, except those indicated, were carried out at $37^{\circ} \mathrm{C}$.

For time-course studies, $10 \mathrm{ml}$ of spore suspension in $50 \mathrm{~mm}$-phosphate buffer $\mathrm{pH} 7.0\left(2.0 \times 10^{8} \mathrm{spores}^{-1}\right)$ was equilibrated in a water bath with shaking at $35^{\circ} \mathrm{C}$ for $10 \mathrm{~min}$ in $100 \mathrm{ml}$ flasks. To this suspension $0.1 \mathrm{ml}$ of ${ }^{3} \mathrm{H}$-labelled substrate $\left(0.1 \mathrm{mM} ; 1.0 \mu \mathrm{Ci} \mathrm{ml}^{-1}\right)$ was added. At different times, samples $(1 \mathrm{ml})$ were quickly filtered

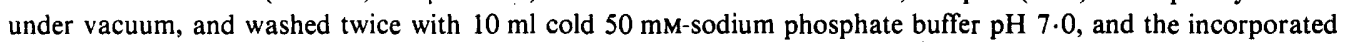
radioactivity was measured. To determine the initial rate of uptake by spores in different stages of germination, tubes containing $0.5 \mathrm{ml}$ of spore suspension were equilibrated as described, and the uptake was initiated by adding $10 \mu l{ }^{3} \mathrm{H}$-labelled substrate. The reaction in each tube was terminated at the appropriate time by adding $10 \mathrm{ml}$ of cold buffer and immediately filtering the mixture through a glass-fibre filter. In some experiments, the reaction mixture contained other non-labelled compounds or metabolic inhibitors, as indicated in the Figure and Table legends. Controls were performed by adding the ${ }^{3} \mathrm{H}$-labelled substrate to the spore suspension and immediately withdrawing samples for estimation of radioactivity; this value was subtracted from the experimental values. The filters were dried and radioactivity was estimated in a toluene-based scintillation fluid [containing $3.5 \mathrm{~g}$ 2,5-diphenyloxazole and $50 \mathrm{mg}$ 1,4-bis-(4-methyl-5-phenyloxazol-2-yl)benzene per litre toluenel, using an Isocap 300 Nuclear Chicago liquid scintillation spectrophotometer.

Respiratory measurements. Measurement of oxygen consumption was carried out at $35^{\circ} \mathrm{C}$ with a Clark oxygen electrode (Yellow Springs Instrument Co., Yellow Springs, Ohio, U.S.A.) as previously described (Hardisson et al., 1978), using $20 \mathrm{~mm}$ glucose, galactose or fructose as substrate.

Dry weight determinations. Samples were withdrawn and dried to constant weight at $90^{\circ} \mathrm{C}$.

\section{RESULTS}

\section{Sugar uptake and respiration by dormant spores}

Dormant spores of $S$. antibioticus obtained from GAE medium took up glucose for at least $30 \mathrm{~min}$ (Fig. 1). The addition of chloramphenicol $\left(100 \mu \mathrm{g} \mathrm{ml}^{-1}\right)$ had no effect on the uptake, indicating that the uptake system was present in the dormant spore, since we have previously shown that the inhibitory effect of chloramphenicol on protein synthesis is immediate (Hardisson et al., 1980). In contrast, no uptake of galactose and fructose by dormant spores was observed. Identical results were obtained when sporulation took place in GAE medium with glucose replaced by galactose or fructose as carbon source. It was possible that some component of yeast extract repressed the uptake systems for galactose and fructose. We therefore studied the uptake of the three sugars by dormant spores obtained from MSM containing glucose, galactose or fructose as the sole carbon and energy source. The results obtained showed that the initial rate of glucose uptake was independent of the carbon source present in the sporulation medium. Again, no uptake of galactose or fructose was found for at least $60 \mathrm{~min}$, even when the dormant spores were obtained by growth of the mycelium in the presence of galactose or fructose.

The $Q_{\mathrm{O}_{2}}$ values for endogenous respiration of suspensions of spores obtained from glucose-MSM, galactose-MSM and fructose-MSM were similar in all three cases [about $10.8 \mu \mathrm{O}_{2} \mathrm{~h}^{-1}$ (mg dry mass) $)^{-1}$. The addition of galactose or fructose had no effect on this value, but the addition of glucose caused an increase in the $Q_{\mathrm{o}_{2}}$ value to $18.0 \mu \mathrm{I} \mathrm{O}_{2} \mathrm{~h}^{-1}$ (mg dry mass) $)^{-1}$.

\section{Sugar uptake by spores in different stages of germination}

Preliminary experiments (results not shown) showed that the rates of uptake of the three sugars during the different stages of germination (dormant, dark and swollen spores) were linear for at least $10 \mathrm{~min}$. We therefore selected a $5 \mathrm{~min}$ period for the determination of the 


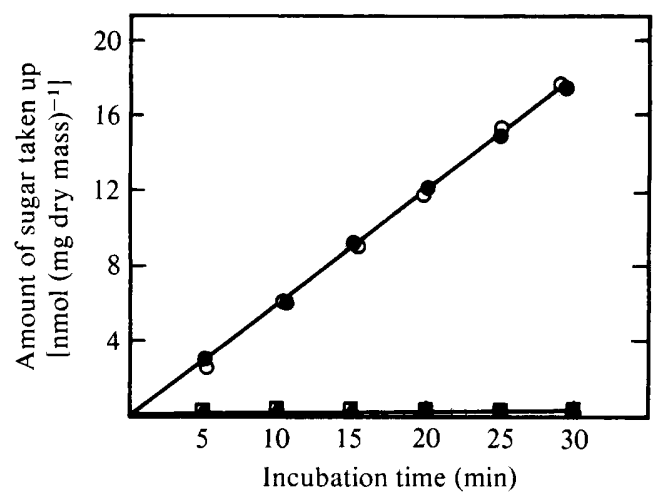

Fig. 1. Time course of sugar uptake by dormant spores of $S$. antibioticus. Dormant spores were suspended in $50 \mathrm{~mm}$-phosphate buffer $\mathrm{pH} 7 \cdot 0$. $\left[{ }^{3} \mathrm{H}\right]$ Glucose, $\left[{ }^{3} \mathrm{H}\right]$ galactose or $\left[{ }^{3} \mathrm{H}\right]$ fructose $(0 \cdot 1 \mathrm{~mm}$; $\left.1.0 \mu \mathrm{Ci} \mathrm{ml}{ }^{-1}\right)$ was added and, at different times, samples $(1 \mathrm{ml})$ were taken and treated as described in Methods: glucose uptake (O); glucose uptake in the presence of chloramphenicol $\left(100 \mu \mathrm{g} \mathrm{ml}^{-1}\right)(\mathbf{O})$; galactose uptake $(\boldsymbol{\Delta})$; fructose uptake $(\square)$.
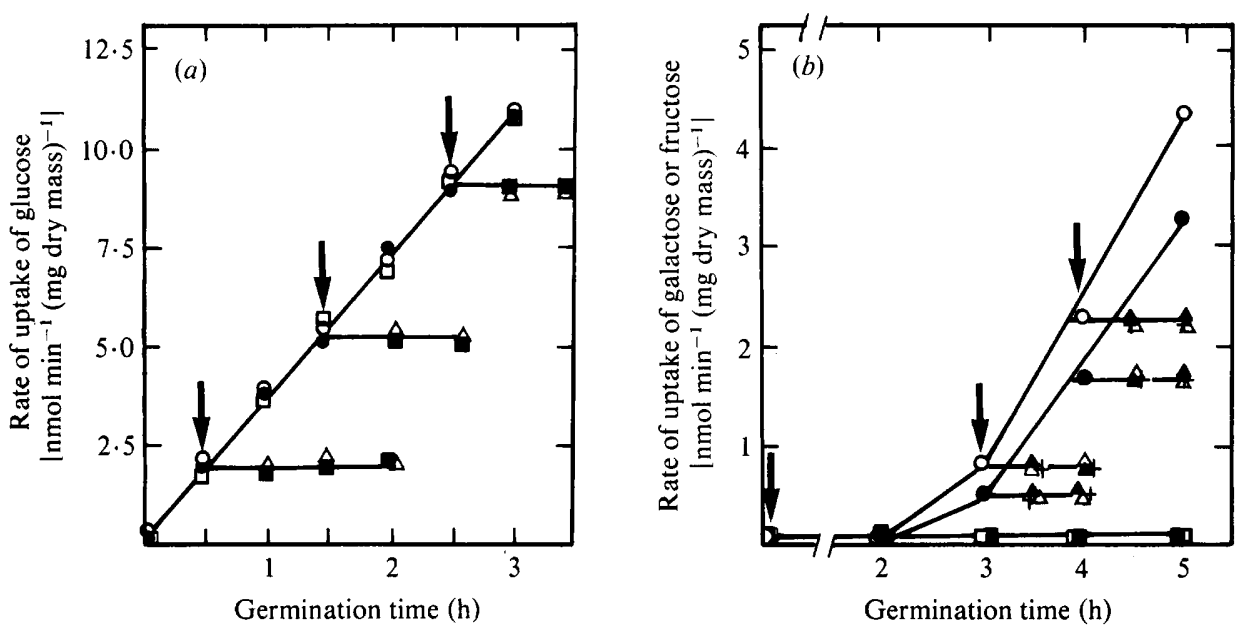

Fig. 2. Rate of uptake of sugars during germination of S. antibioticus spores. (a) Uptake of glucose. Spores were incubated in glucose-MSM (O), galactose-MSM (O) or fructose-MSM ( $\square$ ). At different times, samples were centrifuged, washed twice in $50 \mathrm{mM}$-phosphate buffer $\mathrm{pH} 7.0$ and suspended in the same buffer. The initial rate of $\left[{ }^{3} \mathrm{H}\right]$ glucose $\left(0.1 \mathrm{mM} ; 1.0 \mu \mathrm{Ci} \mathrm{ml}{ }^{-1}\right)$ uptake was immediately determined by means of $5 \mathrm{~min}$ pulses. At the times indicated by the arrows, rifampicin $\left(10 \mu \mathrm{g} \mathrm{ml}^{-1}\right)(\Delta)$ or streptomycin $\left(10 \mu \mathrm{g} \mathrm{m}^{-1}\right)(\square)$ was added, and glucose uptake was followed as before.

(b) Uptake of galactose and fructose. All the conditions were the same as in $(a):\left[{ }^{3} \mathrm{H}\right]$ galactose uptake by spores germinating in galactose-MSM $(\mathrm{O})$ or in glucose-MSM or fructose-MSM $(\square)$; $\left[{ }^{3} \mathrm{H}\right]$ fructose uptake by spores germinating in fructose-MSM $(\odot)$ or in glucose-MSM or galactose-MSM ( $\square$ ). At the times indicated by the arrows, streptomycin $\left(10 \mu \mathrm{g} \mathrm{ml}^{-1}\right)(\Delta)$, rifampicin $\left(10 \mu \mathrm{g} \mathrm{ml}^{-1}\right)(\Delta)$ or glucose $(1 \%, w / v)(+)$ was added, and galactose or fructose uptake was followed as before.

initial uptake rates in subsequent experiments. During spore germination in MSM, the rate of glucose uptake increased continuously, and was independent of the carbon source (Fig. $2 a$ ). When added at different times during germination, rifampicin $\left(10 \mu \mathrm{g} \mathrm{ml}^{-1}\right)$ or streptomycin $\left(10 \mu \mathrm{g} \mathrm{ml}^{-1}\right)$ completely blocked the increase in the uptake rate (Fig. $\left.2 a\right)$. However, galactose or fructose uptake was only observed when the spores germinated in the presence of the respective sugar. Galactose and fructose uptake started after about $2 \mathrm{~h}$ of germination in the 

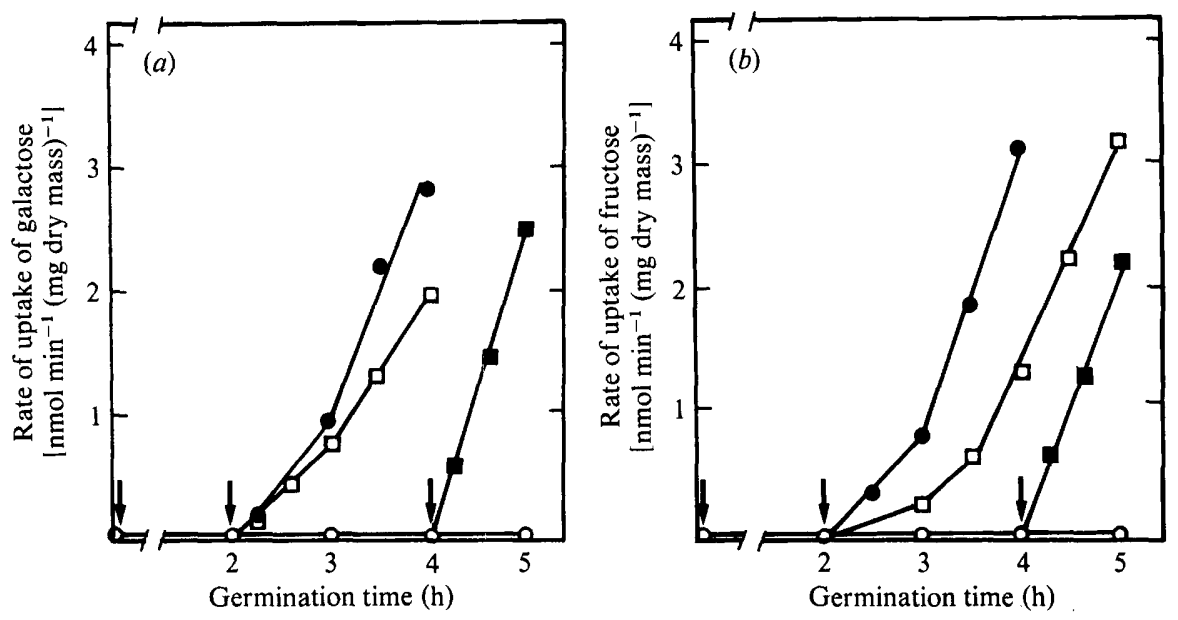

Fig. 3. Influence of the stage of germination of $S$. antibioticus spores on the delay of galactose and fructose uptake. Spores were incubated in the glucose-MSM (O). At the times indicated by the arrows, they were transferred to galactose-MSM $(a)$ or to fructose-MSM $(b)$ and the initial rate of $\left[{ }^{3} \mathrm{H}\right]$ galactose or $\left[{ }^{3} \mathrm{H}\right]$ fructose $\left(0.1 \mathrm{~mm} ; 1.0 \mu \mathrm{Ci} \mathrm{ml}{ }^{-1}\right)$ uptake was determined by means of 5 min pulses: spores transferred immediately (maximum percentage of dormant spores) (O); spores transferred after $2 \mathrm{~h}$ of germination (maximum percentage of dark spores) ( $\square$ ); spores transferred after $4 \mathrm{~h}$ of germination (maximum percentage of swollen spores) (घ).

presence of the sugar, at which time the highest percentage of dark spores was observed. During the next hour rates of galactose and fructose uptake were slow, but they increased considerably during the following $2 \mathrm{~h}$ (Fig. $2 \mathrm{~b}$ ). Addition of rifampicin $\left(10 \mu \mathrm{g} \mathrm{m}^{-1}\right.$ ) or streptomycin $\left(10 \mu \mathrm{g} \mathrm{ml}^{-1}\right)$ at any time before the end of the second hour of germination completely blocked the induction of both uptake systems. If the antibiotics were added after induction had begun, there was no further increase in the uptake rate (Fig. $2 b$ ), which remained constant for at least $6 \mathrm{~h}$.

We also studied the development of the sugar uptake systems when the spores were germinated in the presence of two sugars simultaneously. If one of the sugars was glucose, only the uptake of this sugar was observed. In contrast, both galactose and fructose uptake were observed when the spores were germinated in a mixture of these two sugars. The pattern of uptake was similar to that observed when the spores were germinated in only one of these sugars.

\section{Influence of the stage of germination on the induction time of galactose and fructose uptake}

The stage of germination of the spores had a great influence on the induction time for the galactose and fructose uptake systems. Spores were germinated in glucose-MSM and, at various times, they were centrifuged, washed with phosphate buffer, and resuspended in galactose-MSM or in fructose-MSM. The uptake rate of galactose or fructose was then determined by means of 5 min pulses. The more advanced the germination process, the less the induction time for both sugars (Fig. $3 a, b$ ). Swollen spores showed the shortest induction time. This result is in agreement with our previous findings on respiratory activity and protein synthesis (Hardisson et al., 1978, 1980), both of which show a considerable increase when the spores change from the dark to the swollen stage. The addition of antibiotics at any time during germination completely inhibited the induction of the uptake systems.

\section{Sugar uptake by vegetative mycelium}

Glucose, galactose and fructose uptake was also studied in mycelium in the exponential phase of growth. Similar results to those described for germination were obtained: galactose 
Table 1. Effect of inhibitors on sugar uptake by swollen spores of S. antibioticus

Dormant spores were germinated at $35^{\circ} \mathrm{C}$ in glucose-MSM (for glucose or 2-deoxyglucose uptake), in galactose-MSM (for galactose uptake) or in fructose-MSM (for fructose uptake). When the maximum number of spores had swollen the uptake rates in the presence and absence of $10 \mathrm{mM}-\mathrm{KCN}, 1 \mathrm{mM}$ 2,4-dinitrophenol (DNP) or $0.25 \mathrm{~mm}$-p-chloromercuribenzoate ( $p$-CMB) were determined by $5 \mathrm{~min}$ pulses. The results shown are the means of four independent experimental values.

\begin{tabular}{|c|c|c|c|c|}
\hline \multirow[b]{2}{*}{ Inhibitor } & \multicolumn{4}{|c|}{ Rate of uptake of sugar [nmol $\min ^{-1}$ (mg dry mass) ${ }^{-1}$ ] } \\
\hline & Glucose & Galactose & Fructose & 2-Deoxyglucose \\
\hline None & $15 \cdot 32$ & $4 \cdot 25$ & $3 \cdot 12$ & $14 \cdot 58$ \\
\hline $\mathrm{KCN}$ & $2 \cdot 14(86)^{*}$ & $0.21(95)$ & $0.31(90)$ & $2.77(81)$ \\
\hline 2,4-DNP & $5 \cdot 51(64)$ & $0.42(90)$ & $0.40(87)$ & $4 \cdot 22(71)$ \\
\hline p-CMB & $1.83(88)$ & $0.59(86)$ & $0.47(85)$ & $2.33(84)$ \\
\hline
\end{tabular}

or fructose uptake was observed only when the mycelium was grown in the presence of the respective sugar; glucose uptake was always observed at the same rate, independent of the carbon source of the culture medium.

\section{Effect of glucose on the galactose and fructose uptake systems}

Spores germinating in galactose-MSM or in fructose-MSM developed increasing uptake activities for those sugars from the second to at least the fifth hour of germination. The addition of glucose $(1 \%, \mathrm{w} / \mathrm{v})$ to germinating spores in these media, followed by subsequent assays of galactose or fructose uptake in the absence of glucose, indicated that glucose inhibited further development of the uptake activities for those sugars (Fig. $2 b$ ). Thus glucose effectively halted the induction of additional uptake activity, whilst allowing the previously developed capacity to continue. We also determined the effect of the presence of glucose on the uptake rates of both sugars under non-proliferating conditions (50 mM-phosphate buffer, $\mathrm{pH} 7.0)$. Glucose $(0.1 \mathrm{~mm})$ inhibited galactose uptake $(0.1 \mathrm{~mm})$ by about $95 \%$. However, fructose uptake $(0.1 \mathrm{mM})$ was only partially inhibited by glucose: the inhibition was $15-25 \%$ at $0.1 \mathrm{~mm}$-glucose and $40-50 \%$ at $2 \mathrm{~mm}$-glucose.

\section{Effect of analogues and metabolic inhibitors on sugar uptake}

Glucose uptake $(0.1 \mathrm{mM})$ was inhibited by $50 \%$ by its analogue 2-deoxyglucose at equimolar concentration, and the inhibition increased at higher concentrations. In contrast, 2-deoxyglucose had no effect on galactose and fructose uptake, when in 100-fold excess. Other analogues such as methyl $\alpha$-D-glucoside and methyl $\beta$-D-thiogalactoside had no effect on glucose and galactose uptake, respectively. 3-O-Methylglucose partially inhibited $0.1 \mathrm{mM}$-glucose uptake ( $66 \%$ at a concentration of $1.0 \mathrm{~mm})$.

The uptake of the three sugars by swollen spores was strongly inhibited by the respiratory inhibitor potassium cyanide and the uncoupler of oxidative phosphorylation 2,4dinitrophenol, and also by the thiol reagent $p$-chloromercuribenzoate (Table 1). Uptake of 2-deoxyglucose was also inhibited by these agents to about the same extent as the uptake of glucose.

\section{Effect of temperature on sugar uptake}

The optimum temperature for glucose uptake was $40^{\circ} \mathrm{C}$, and for galactose and fructose uptake $45^{\circ} \mathrm{C}$. For all three sugars, uptake was observed between 20 and $55^{\circ} \mathrm{C}$. Outside this range, no significant uptake was observed. 


\section{DIS CUSSION}

Few studies have been made of sugar transport in Streptomyces, and these were carried out on mycelium. We studied the sugar uptake systems in various stages of the developmental cycle. Streptomyces antibioticus shows differences in the utilization of sugars as the sole carbon and energy source for germination (Hardisson et al., 1978). Our present results show that, of the three sugars examined, only glucose was taken up by dormant spores, even when the spores were obtained from organisms grown with galactose or fructose as the only carbon and energy source. The glucose uptake system was probably present in the dormant spore, since chloramphenicol did not affect this uptake. These results are supported by the fact that only glucose addition increased the $Q_{\mathrm{O}_{2}}$ values of dormant spores. We believe that the glucose uptake system is constitutive in the dormant spore. Several hypotheses could explain the absence of galactose and fructose uptake by dormant spores: (i) the transport systems for galactose and fructose might be inactivated during sporulation; (ii) the aerial mycelium from which the spores were derived could have fed on the lysing substrate mycelium, and thus never used the sugar present in the culture medium; (iii) glucose derived from the hydrolysis of glycogen could be used as the sole carbon source and, at the same time, repress the synthesis of the galactose and fructose uptake systems. We have demonstrated (unpublished results) the existence of reserve polymers (glycogen) in stationary phase $S$. antibioticus grown on glucose, and we believe that these polymers are also accumulated during growth on galactose and fructose.

During spore germination, glucose uptake was independent of the carbon source of the germination medium, and the increase in the glucose uptake rate was dependent on protein and RNA synthesis. Galactose and fructose uptake systems were inducible after a delay of about $2 \mathrm{~h}$, and were also dependent on protein and RNA synthesis. The time necessary for the induction of either sugar uptake system to begin was related to the germination stage of the spores. Dormant, dark and swollen spores showed progressively shorter induction times. This is probably related to the greater metabolic and biosynthetic activity in the last stages of germination (Hardisson et al., 1978, 1980). Vegetative mycelium in the exponential phase of growth showed a similar pattern of sugar uptake: constitutive for glucose, and inducible for galactose and fructose.

Inhibition of the induction of galactose and fructose uptake systems by glucose, rifampicin and streptomycin was observed. However, the uptake rate for both sugars remained constant for at least $6 \mathrm{~h}$, showing that degradation of the transport system did not take place. The effect of glucose may have been realized either by the glucose itself or by some catabolite of it which might repress the expression of the structural genes for the galactose and fructose uptake systems.

The glucose analogue, 2-deoxyglucose, did not affect uptake of galactose and fructose in non-proliferating conditions, thus excluding the possibility of an effect at the transport level. Uptake of all three sugars required the presence of free thiol groups and was affected by respiratory inhibitors, thus suggesting, but not proving, that sugar uptake was by active transport. 2-Deoxyglucose strongly inhibited glucose uptake. The inhibition of 2deoxyglucose uptake by the inhibitors investigated was quantitatively similar to that found for glucose uptake.

Sabater \& Asensio (1973) found three independent, constitutive systems for the uptake of glucose, fructose and mannose by mycelium of $S$. violaceoruber. Our results show that in mycelium of $S$. antibioticus only glucose uptake was constitutive, galactose and fructose uptake being inducible. Tang (1977) has reported that fructose uptake by mycelium of $S$. venezuelae was also inducible. All these results show a great variability in the regulation of sugar uptake systems of Streptomyces species.

Spores of $S$. violaceoruber incorporated glucose, but not fructose or mannose (Sabater \& Asensio, 1973). These authors suggested that during germination the appearance of constitutive and independent uptake systems for these sugars takes place. We have studied in 
more detail the uptake systems for glucose, galactose and fructose during spore germination. Our results clearly show that only glucose uptake was constitutive at all stages of development, whereas galactose and fructose uptake systems were inducible. Spores obtained from mycelium grown with either galactose or fructose as sole carbon source have lost, at some stage in their development, the ability to take up those sugars. They can only regain these transport activities if re-induced with these sugars, and this re-induction is more effective in the later stages of germination.

The authors thank Professor Sir Hans Kornberg and Dr M. C. Jones-Mortimer for helpful discussions and critical reading of the manuscript. J.A.S. was the recipient of a pre-doctoral fellowship from the Spanish Ministry of Education.

\section{REFERENCES}

Atrwell, R. W. \& Cross, T. (1973). Germination of actinomycete spores. In The Actinomycetales: Characteristics and Practical Importance, pp. 197207. Edited by G. Sykes \& F. A. Skinner. London \& New York: Academic Press.

Gross, W. \& BurkhardT, K. L. (1973). Multiple transport systems for basic amino acid transport in Streptomyces hydrogenans. Biochimica et biophysica acta 298, 437-445.

Hardisson, C., Manzanal, M. B., Salas, J. A. \& SuÁREZ, J. E. (1978). Fine structure, physiology and biochemistry of arthrospore germination in Streptomyces antibioticus. Journal of General Microbiology 105, 203-214.

hardisson, C., Salas, J. A., Guijarro, J. A. \& SuÁREZ, J. E. (1980). Macromolecular synthesis during germination of Streptomyces spores in a chemically defined medium. FEMS Microbiology Letters 7, 233-235.

HiRsCH, C. F. \& ENSIGN, J. C. (1975). Germination of Streptomyces viridochromogenes spores. In Spores $V I$, pp. 28-35. Edited by P. Gerhardt, R. N. Costilow \& H. L. Sadoff. Washington, D.C.: American Society for Microbiology.

HiRsCh, C. F. \& ENSIGN, J. C. (1976a). Nutritionally defined conditions for germination of Streptomyces viridochromogenes spores. Journal of Bacteriology 126, 13-23.

Hirsch, C. F. \& Ensign, J. C. $(1976 b)$. Heat activation of Streptomyces viridochromogenes spores. Journal of Bacteriology 126, 24-30.

KalakoutskiI, L. V. \& Pouzharitskaja, L. M. (1973). The Streptomyces spore: its distinct features and germinal behaviour. In The Actinomycetales: Characteristics and Practical Importance, pp. 155178. Edited by G. Sykes \& F. A. Skinner. London \& New York: Academic Press.

RiNG, K., EHLE, H. \& FoIT, B. (1976). Effect of alkali ions on the active transport of neutral amino acids into Streptomyces hydrogenans. Biochimica et biophysica acta 433, 615-629.

Ring, K., Gross, W., Ehle, H. \& FoIT, B. (1977). Characterization of L-aspartate uptake by Streptomyces hydrogenans. Journal of General Microbiology 103, 307-317.

SABATER, B. \& AsENSIO, C. (1973). Transport of hexoses in Streptomyces violaceoruber. European Journal of Biochemistry 39, 201-205.

TANG, T. (1977). Fructose uptake activity in Streptomyces venezuelae. FEMS Microbiology Letters 1, 183-186. 